\title{
Intervenções sobre as superfícies urbanas: dissenso, consenso e ambivalências em Londres ${ }^{1}$
}

\author{
Laura Guimarães Corrêa' \\ https://orcid.org/0000-0002-7218-1782 \\ I - UFMG \\ Belo Horizonte (MG), Brasil
}

Resumo: Intervenções urbanas são práticas comunicacionais inscritas nas superfícies das cidades, que rompem a normalidade e interferem na paisagem e no cotidiano urbanos. Muitas intervenções podem ser lidas como ações políticas e gerar diversos significados, com reverberações e impactos positivos e negativos. Este artigo adota os conceitos de dissenso / consenso e política / polícia em Rancière para detectar reivindicações e empreender a análise de duas intervenções urbanas realizadas em Londres nos anos de 2015 e 2016. Ao analisar esses casos, observa-se que discursos hegemônicos podem se apropriar de intervenções urbanas, assim como manifestações criativas e ativistas contemporâneas podem se tornar consenso, como parte dos crescentes fenômenos de gentrificação e comodificação do espaço urbano. Esses processos são permeados pela lógica neoliberal e trazem consigo as contradições, a complexidade e as ambivalências presentes no dia-a-dia das cidades contemporâneas.

Palavras-chave: intervenções urbanas; dissenso; consenso; ambivalência.

Abstract: Interventions over urban surfaces: dissensus, consensus and ambivalences in London - Urban interventions are communicational practices inscribed on the surfaces of cities, which disrupt normality and interfere in their landscape and everyday life. Many interventions can be read as political actions and generate diverse meanings, with positive and negative impacts and reverberations. This article adopts Rancière's concepts of dissensus / consensus and politics / police in order to detect claims and undertake the analysis of two urban interventions in London in 2015 and 2016. I observed that hegemonic discourses can appropriate urban interventions, as well as contemporary creative and activist manifestations can become

1 Este artigo traz reflexões iniciadas nas pesquisas "Escritas urbanas sobre o discurso autorizado: expansão e internacionalização da pesquisa", financiada pela Fapemig (Fundação de Amparo à Pesquisa do Estado de Mi-nas Gerais); e "Urban writings over the official discourse: tension, appropriation and resistance", desenvolvida com apoio da Capes (Coordenação de Aperfeiçoamento de Pessoal de Nível Superior), agências às quais agradeço. 
consensus, as part of the increasing phenomena of gentrification and commodification of urban space. These processes are permeated by the neoliberal rationale and bring with them the contradictions, the complexity and the ambivalences in contemporary cities.

Keywords: urban interventions; dissensus; consensus; ambivalence.

\section{Introdução}

Intervenções urbanas são práticas comunicacionais realizadas e inscritas nas cidades, geralmente em suas superfícies, que rompem a normalidade e interferem em seu cotidiano e em sua paisagem. Muitas intervenções podem ser lidas como ações políticas e gerar diversos significados, com reverberações e impactos positivos e negativos.

Este artigo traz reflexões que partiram de uma pesquisa ${ }^{2}$ que teve como objetivo identificar e analisar a emergência e os significados de intervenções visuais em Londres. Ao longo de meses, formas diversas de intervenções urbanas como graffiti, tagging, protestos visuais, stickers, estêncil etc. foram observadas, coletadas e analisadas, a fim de compreender esse fenômeno da comunicação em um contexto sociocultural amplo e investigar seu potencial para consenso e dissenso. Nos casos eleitos para discussão neste artigo, um grupo anarquista (Class War) e um famoso artista de rua (Banksy) utilizaram diferentes táticas, técnicas e ferramentas comunicacionais para que seus protestos fossem vistos, reproduzidos e midiatizados; e essas ações trouxeram novos significados, múltiplos efeitos e consequências.

A abordagem proposta considera que as superfícies urbanas são espaços de mediação na vida cotidiana, que carregam significados e revelam tensões e ambivalências sobre questões que afetam as pessoas em determinados tempos e lugares. Considera ainda que o viver na cidade é instância importante para os processos de subjetivação, isto é, para as formas pelas quais os sujeitos se constituem, nas interações e embates com os discursos visuais urbanos. Ao adotar os conceitos de dissenso / consenso e de política / polícia propostos por Jacques Rancière para observar o objeto de pesquisa, foi possível detectar essas reivindicações e empreender a análise de intervenções urbanas realizadas em duas regiões distintas de Londres nos anos de 2015 e 2016: um protesto antigentrificação e uma obra de arte de rua.

O artigo é dividido em cinco seções. Primeiramente, argumento que as superfícies da cidade são potentes suportes para a comunicação e que intervenções urbanas devem ser consideradas fenômenos comunicacionais e, portanto, espaços para subjetivação e ação política. Em seguida, exploro os conceitos de consenso e dissenso (RANCIÈRE, 1996, 2009, 2015) para analisar o fenômeno das intervenções. Na seção seguinte, fundamento e descrevo o percurso metodológico da pesquisa de forma a explicitar como os temas

2 Estágio pós-doutoral na London School of Economics and Political Science, Reino Unido, com bolsa Capes Coordenação de Aperfeiçoamento de Pessoal de Nível Superior. 
emergiram nas derivas. Apresento oito exemplos fotográficos de intervenções (stickers, em sua maioria) que ilustram a emergência dos temas e justificam a seleção dos dois casos analisados. Após apresentar e discutir as duas intervenções em Londres, desenvolvo a análise dos fenômenos considerando as ideias de consenso, dissenso, apropriação e ambivalência. Na última seção, apresento as considerações finais, retomando os conceitos de Rancière e a contribuição de outros/as autores/as para discutir as práticas de intervenção como ações políticas e cenas de dissenso.

\title{
Mediações, superfícies e comunicação urbana
}

\begin{abstract}
Se comparo a cidade a um livro, a uma escrita (a um sistema semiológico), não tenho o direito de esquecer seu caráter de mediação. Não posso separá-la nem daquilo que ela contém, nem daquilo que a contém, isolando-a como se fosse um sistema completo. [...] Sobre esse livro, com essa escrita, vêm-se projetar formas e estruturas mentais e sociais. (Henri Lefebvre, $\mathrm{n}^{\prime} \mathrm{O}$ direito à cidade)
\end{abstract}

Um dos conceitos importantes para se ler a cidade é o de mediação, desenvolvido por Martín-Barbero (1987). O autor entende que as mediações estão imbricadas com as dimensões simbólicas da construção do coletivo, que apontam as possibilidades interpretativas nas relações com os discursos da mídia. Parte crucial da vida cotidiana, a mediação pode ser compreendida como um espaço entre a cultura, a comunicação e a política em relação dialética com as lógicas da produção e do consumo, os formatos industriais e as matrizes culturais (LOPES, 2014).

A cidade contemporânea pode ser interpretada como um espaço de mediação, como um sistema complexo onde significados circulam constantemente, por múltiplas tecnologias em contextos social e institucionalmente diversos, construindo e sendo construído pela(s) cultura(s). Para Silverstone (2002), a mediação é tanto social quanto tecnológica, dependendo cada vez mais da presença dos media na vida cotidiana e do papel fundamental que estes e as tecnologias de comunicação exercem nas nossas vidas. Os media facilitam e estruturam espaços para a comunicação, interação e ação. Assim, de forma mais abrangente, podemos interpretar a mídia como uma materialidade, um ambiente e um enquadramento (ANTUNES eVAZ, 2006), que compreende esferas de ação e limitações, que viabiliza e impede certas formas e tipos de discurso.

Superfícies urbanas podem ser consideradas plataformas midiáticas - e das mais presentes na vida cotidiana. Cidades são lugares em que processos de subjetivação e de identificação acontecem; imagens, textos e interações na paisagem urbana oferecem modos de ser, pensar e agir. Entretanto, esses processos não são predeterminados ou imutáveis, eles são repletos de tensões e negociações sobre culturas, valores, normas, direitos. Como aponta Ângela Marques (2014, p. 132), o sujeito está "enredado em relações discursivas 
de poder, [...] numa constante tensão entre operações conectadas e indissociáveis: assujeitamento e subjetivação; dominação e passividade; subjugação e autonomia; ação e resistência". Além disso, as práticas cotidianas de interação são complexas - e dificilmente explicadas ou contidas em dicotomias. Consequentemente, há diversos modos com que moradores da cidade consomem, agem e reagem aos discursos urbanos da vida cotidiana. Construímos nossa identidade e subjetividade em relação com o/a outro/a, e isso é um fenômeno comunicativo reflexivo.

Superfícies urbanas interferem nas maneiras de vermos a nós mesmos e de habitarmos a cidade que contém marcas, traços e sinais da experiência urbana vivida e compartilhada. Compreendo superfícies urbanas como a parte exterior da cidade, em sentido amplo. A superfície é o que é visível, sensível, no sentido estético: o que pode ser capturado pelos sentidos visuais e táteis na nossa experiência cotidiana na urbe. As superfícies estão relacionadas à aparência e à emergência; são a camada exterior das cidades, desenhadas e construídas de acordo com seu propósito e função: cobrir, proteger, esconder, mostrar. As superfícies são telas em potencial, eventualmente utilizadas por pessoas anônimas, comerciantes, artistas e ativistas como espaços para a comunicação e a visibilidade, assim como para protestos e reivindicações. Assim, os equipamentos urbanos e suas superfícies podem separar mas também mediar, comunicar. Expostas e vulneráveis, as superfícies urbanas não são estáticas, pois mudam à medida em que cidades e sociedades se transformam. Apesar da proibição e controle de discursos visuais não-oficiais, a urbe é um espaço de heterogeneidade, onde indivíduos e grupos de origens e estratos diversos são separados e conectados.

A comunicação urbana, assim como outras formas de comunicação mediada, tende a ser assimétrica. A perspectiva de Michel de Certeau para pensar as ações dos indivíduos e as relações de força na sociedade é de grande valia para a análise das intervenções urbanas. Apesar das assimetrias, controles e dinâmicas de poder, algumas pessoas e grupos subalternizados tendem a subverter os usos e funções de lugares e objetos cotidianos, como discutido por Certeau. Essas práticas são a marca do fraco, cujas práticas engenhosas respondem e atacam os lugares de poder no território inimigo. Certeau utiliza o conceito estratégias para nomear as ações dos poderosos e táticas para aquelas dos fracos a fim de evidenciar a diferença de poder - e de tipo de ação - entre eles. A estratégia é, assim, ligada às instituições dominantes, trata-se da estrutura habitual; as táticas são as práticas da vida cotidiana que dependem de oportunidades, do uso da criatividade e da astúcia no domínio dos poderosos. A ação tática está baseada em uma “(...) quase-invisibilidade, pois ela quase não se faz notar por produtos próprios (onde teria o seu lugar?) mas por uma arte de utilizar aqueles que lhe são impostos." (CERTEAU, 2005, p. 94).

Se a mediação constitui-se como um espaço entre a cultura, a comunicação e a política, as táticas de estar, atuar e ser ouvido/a na cidade mediada são maneiras de se fazer política por meio da comunicação em suas superfícies. A cidade é, portanto, lugar 
das estratégias e das táticas, da polícia e da política, de consenso e de dissenso, como discuto a seguir a partir dos conceitos de Rancière e sua articulação com as ideias aqui apresentadas.

\section{Dissenso e consenso, política e polícia}

O filósofo Jacques Rancière $(1996,2009,2015)$ propõe o conceito de dissenso para que se possa compreender situações nas quais a ordem é perturbada por alguém que supostamente não deveria fazer parte do debate e das decisões públicas. A discussão proposta por Rancière é relacionada aos limites da vida política e privada. Assim, quem define esse limite tem o poder de decidir o que pode ser discutido publicamente ou não, o que tem mais importância na vida da comunidade, da cidade, do país. Para ele, dissenso "[...] consiste na rejeição de toda diferença que distingue pessoas que 'vivem' em diferentes esferas da existência, a destituição de categorias de pessoas que são ou não são qualificadas para a vida política." (RANCIÈRE, 2015, p. 77).

O autor propõe uma definição específica de política e polícia como conceitos opostos. Sua definição de política considera seu caráter perturbador, sua capacidade de romper a ordem mudando o modo como as coisas são vistas, isto é, interferindo na distribuição do sensível. Nesse sentido, a política é relacionada à estética, consistindo na emergência pública daqueles que não tinham voz para participarem do trabalho poético, criativo e intelectual. Então, arte e política podem ser emancipatórias, podendo criar - ou pelo menos indicar - um novo mundo, uma nova forma de existência e compartilhamento do comum: "A política começa quando tornam visível o invisível e fazem o que era considerado o mero ruído de corpos sofredores ser ouvido como um discurso sobre o 'comum' da comunidade." (RANCIÈRE, 2015, p. 147)

O filósofo define a polícia como a distribuição hierárquica na qual indivíduos têm lugares específicos e determinados. Nesse sentido, a política formal (constituída de partidos, Estado, governo, assim como uma oposição estabelecida, sindicatos etc.) são parte daquilo que Rancière denominaria a ordem da polícia. Não há falta ou sobra na ordem da polícia, que acontece através de divisões e repartições de quem pode falar e o que pode ser dito. Em oposição ao dissenso, considerado por Rancière como a essência da política, o consenso é o processo que reduz o espaço político. Consenso não significa que todos concordam em todas as questões, mas que há um acordo sobre como o sensível é distribuído, sobre quem possui e quem não possui o direito de falar e ser reconhecido como uma voz que importa.

Argumento, assim, que consenso e dissenso podem ser conceitos proveitosos para se ler, interpretar e analisar interações urbanas. Interferências escritas e realizadas ("performadas") nas ruas são práticas comunicativas que podem mostrar cenas de dissenso, marcando uma nova distribuição do sensível. Nesse caso, o sujeito autônomo, que cria e é criado nesse processo, concebe um cenário com aspectos contingentes, situacionais, 
estéticos e políticos. Práticas de interferência urbana ilegais - ou mesmo agressivas são sujeitas à apropriação, normalização e relativa neutralização, aproximando-se do que Rancière define como consenso. Ao observar os variados e contínuos diálogos que ocorrem na cidade, é possível perceber que dissenso e consenso estão em jogo, por vezes em situações nas quais ambos estão presentes. As táticas dos fracos, para usar os termos de Certeau (2005), podem ser apropriadas em ações dos poderosos, que tendem a mudar suas estratégias de acordo com as circunstâncias. Assim, as fronteiras entre essas instâncias podem se mover e se transformar. Essas reflexões levam à questão principal da pesquisa: se, em cidades globais contemporâneas, dissenso tende a se tornar consenso por meio de comodificação e apropriação, as intervenções urbanas podem ter um sentido mais amplo e político?

\section{Percurso metodológico e seleção dos casos}

Londres é uma cidade culturalmente rica e diversa, um universo privilegiado para a realização de uma pesquisa sobre comunicação urbana visual. A identidade da capital britânica está relacionada com o seu poder econômico, histórico, político e militar; fortemente conectada a um poder simbólico (GEORGIOU, 2013), o que faz dela uma cidade global icônica. Em World City, Massey (2007) destaca que Londres mantém uma posição hegemônica no coração do neoliberalismo. A autora também descreve Londres como um lugar radical e progressista que tem sido foco de imigração, o que faz da metrópole um "lar para uma multiplicidade impressionante de etnicidades e cultura» (MASSEY, 2007, p. 9. Tradução minha), além de ser uma das cidades mais ricas do mundo, que contém e mantém desigualdades acentuadas e crescentes.

O material empírico da pesquisa não foi predeterminado, mas definido indutivamente durante a pesquisa. A metodologia escolhida foi uma exploração etnográfica das ruas de Londres, com atenção e abertura para os diálogos visuais nas ruas da cidade. Os limites espaciais para a pesquisa foram definidos de acordo com as zonas de transporte londrinas, privilegiando as zonas 1 e 2. Minha busca por intervenções discursivas foi inspirada pela ideia de flânerie em Benjamim $(1997,2004)$ que foi, por sua vez, inspirado pelo flâneur de Baudelaire (2007), um viajante excêntrico esteticamente afetado pela experiência cosmopolita. Georgiou (2013, p.18. Tradução minha) destaca que flânerie não era uma prática de exploração estética para Benjamim: ele procurava entender a cidade "como um lugar de luta, um lugar desigual", e também como "um ponto de encontro de diferenças".

Por meio dessa prática, aprendi a detectar e selecionar regiões e ruas mais propensas a receber intervenções visuais. Algumas das escolhas foram feitas com planejamento, outras foram feitas espontaneamente durante as caminhadas. Nesse contexto, meu método também foi inspirado pelas práticas situacionistas das derivas, como proposto por Guy Debord (1956. Tradução minha): “o campo especial de uma deriva pode ser preciso ou vago, 
a depender do objetivo: se a atividade visa a estudar um terreno ou se busca resultados afetivos desviantes e surpreendentes". Assim, a metodologia da deriva levou a um conhecimento do cenário urbano e a imprevisíveis achados. O percurso metodológico foi costurado junto ao trabalho conceitual e teórico, como a atenção às táticas dos fracos tendo em vista as estratégias dos poderosos (CERTEAU, 1984), assim como a cenas de dissenso e consenso (RANCIÈRE, 2009; 2015). Uma característica importante da comunicação visual urbana, tanto legal quanto ilegal, tanto oficial quanto transgressora, é que essas práticas interacionais falam de um certo tempo e local, revelando tensões contemporâneas, reverberando problemas em pauta na sociedade, mostrando as reivindicações nos centros urbanos.

A partir das imagens coletadas - cerca de duas mil fotografias de intervenções sob formas diversas como textos em tinta spray, adesivos (stickers), stêncil, arte de rua etc. - fiz uma primeira seleção de acordo com critérios de qualidade, inteligibilidade e adequação às questões da pesquisa. As imagens selecionadas foram então impressas e cortadas. Para obter uma visão geral da empiria, distribuí espacialmente todo o material e testei a construção de possíveis grupos para análise. Através destes procedimentos, pude detectar regularidades, peculiaridades e diferenças entre as intervenções registradas. As perguntas relacionadas ao conteúdo e ao tema da intervenção foram: 1) o que essa pessoa ou grupo reivindica?, 2) a intervenção aponta para um conflito?, e 3) o que as práticas de escrita podem revelar sobre as tensões em Londres? Entre os temas mais presentes nas intervenções urbanas nas superfícies de Londres, percebi que a habitação, a gentrificação (Figuras 1 , 2, 3 e 4) e a questão dos refugiados (Figuras 5, 6, 7 e 8) eram muito visíveis na cidade.

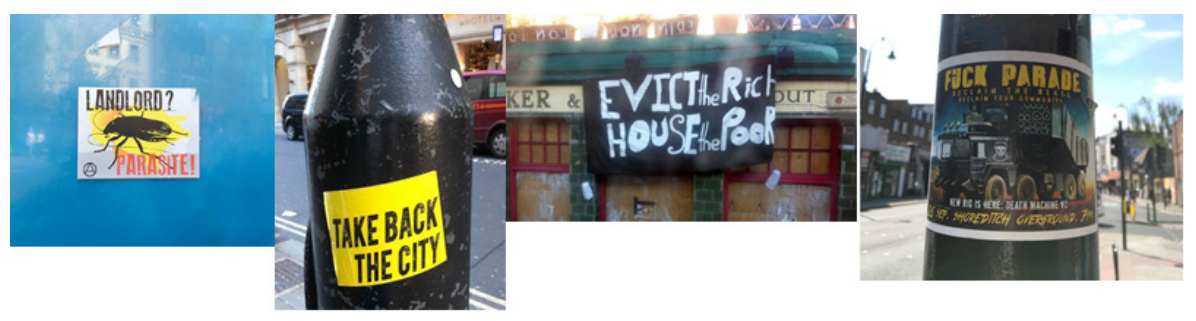

Figs.1, 2, 3 e 4 (da esquerda para a direita). Intervenções relacionadas à habitação, à gentrificação e aos conflitos sobre o espaço urbano. Dados de pesquisa. Londres, 2015 e 2016.

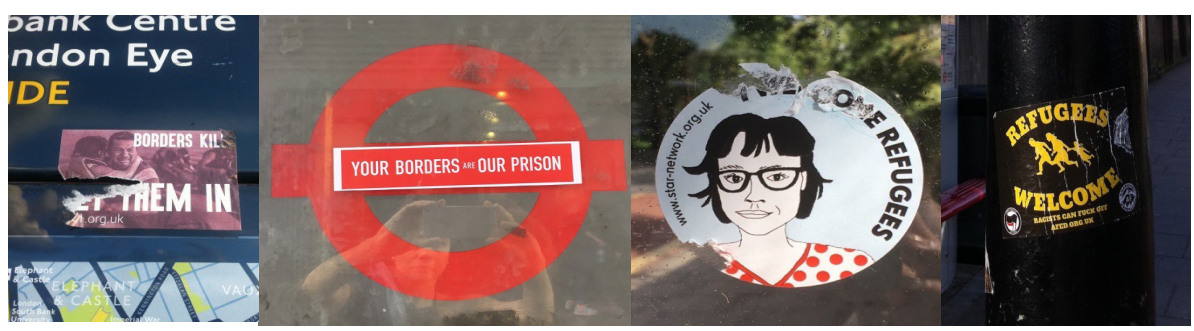

Figs. 5, 6, 7 e 8 (da esquerda para a direita e abaixo). Intervenções relacionadas às fronteiras, à presença e ao (não) acolhimento de pessoas refugiadas. Dados de pesquisa. Londres, 2015 e 2016. 


\section{Protesto, arte urbana e ambivalência}

A pesquisa nas ruas de Londres chamou minha atenção, assim, para os temas da habitação / gentrificação e da chamada crise dos refugiados. Enquanto estive realizando pesquisa na cidade, algumas intervenções urbanas tiveram maior destaque na rua e nos media. Neste artigo, apresento dois estudos de caso distintos, mas que apresentam similaridades. Em cada um desses casos, discursos dissidentes desafiaram discursos e espaços consensuais anteriormente existentes em Londres, provocando diferentes reações e resultados. Uma das intervenções ocorreu no leste da cidade, onde os processos de gentrificação são muito visíveis. A outra intervenção aconteceu em Knightsbridge, que fica na rica região de Kensington e Chelsea. O critério para a escolha dessas intervenções foi a ruptura e a visibilidade midiática: ambas causaram quebras, mesmo que efêmeras, na paisagem e no cotidiano dessas regiões.

\section{Gentrificação e antigentrificação no leste de Londres}

Em cidades globais em todo o mundo, bem como em cidades históricas menores, as questões e lutas sobre habitação estão presentes. Sharon Zukin explica que a gentrificação é "o movimento de pessoas ricas e com alta escolaridade para regiões de população de baixa renda, e o alto valor dos imóveis que segue essas pessoas, transformando um bairro decadente numa área com charme histórico ou hipster." (ZUKIN, 2010, p.8. Tradução minha). Esse fenômeno contemporâneo leva a tensões e conflitos em relação ao uso complexo de espaços públicos e privados.

De acordo com Rancière (1996), o dissenso é um desacordo sobre os limites entre o que é público e o privado. Os problemas da gentrificação, como muitas outras questões urbanas, são ligados à relação e à disjunção entre a vida pública e a vida privada: o aumento de aluguéis afeta onde e como as pessoas vivem na cidade. Isso pode ser visto como um problema privado e individual, que precisaria ser resolvido, por exemplo, com o aumento da renda familiar ou a mudança para uma área menos cara. No entanto, quando indivíduos e grupos se organizam para discutir e protestar sobre o custo da habitação, este se torna um problema público. As reivindicações contra a gentrificação e a especulação imobiliária estão inscritas nesse esforço para tornar visível o fenômeno de deslocamento em alguns bairros em Londres. Essas disputas de sentido são cada vez mais presentes na cidade que Massey (2015) descreve como um lugar cada vez mais desigual.

A primeira intervenção analisada foi realizada por um grupo organizado de ativistas: em setembro de 2015, manifestantes antigentrificação atacaram um café no leste de Londres. Tanto a área (Shoreditch) quanto a rua (Brick Lane) são famosas pela sua diversidade cultural e pela consequente "autenticidade". A população era composta principalmente por imigrantes de países do sul da Ásia que se estabeleceram na região, 
que vem sendo gradativamente ocupada por bares, cafés, galerias de arte, butiques e outros estabelecimentos atraentes para turistas e londrinos à procura de um lugar charmoso e relativamente barato para se hospedar ou morar. A população de Shoreditch ainda é muito diversa, mas os aluguéis vêm aumentando a um ritmo acelerado, dificultando a permanência de antigos e atuais moradores.

Criado por dois gêmeos de Belfast que cabem no estereótipo do hipster3, o Cereal Killer Cafe provocou controvérsia desde a sua abertura na Brick Lane em 2014, uma vez que os preços altos foram considerados ultrajantes para uma das regiões mais pobres de Londres. Ativistas e até mesmo a imprensa apontaram para a discrepância entre os dois fatos, argumentando que moradores locais não podiam comer lá. Neste contexto, o Cereal Killer Cafe foi escolhido como alvo de um protesto público organizado através de uma página do Facebook chamada Fuck Parade. O protesto foi organizado por um grupo anarquista chamado Class War (Guerra de Classe), que existe desde 1983 no Reino Unido e realiza ações e manifestações, geralmente de cunho bastante agressivo, contra a monarquia e as classes dominantes.

Além da página do Facebook, o grupo usou adesivos em postes para mobilizar a população. Na noite do protesto, os ativistas antigentrificação usaram máscaras de porco e carregaram tochas acesas, o que assustou clientes que estavam dentro do café. Manifestantes jogaram tinta vermelha e pintaram a palavra "escória" sobre suas janelas, tratando a loja como um símbolo da gentrificação. Poucos minutos depois de seu início, o evento reverberou no Twitter e outras redes sociais, assim como em grandes jornais do Reino Unido algumas horas depois.

No dia seguinte, a tinta vermelha que permaneceu em algumas partes da fachada não contrastava muito com o estilo gráfico da marca e das ilustrações do café. Em uma área conhecida por graffiti, arte de rua e intervenções, a tinta poderia ser parte da identidade visual do estabelecimento, que já trazia referências de informalidade, como tipografia retrô, fortes cores primárias etc. A manifestação não parece ter perturbado o negócio, muito pelo contrário: uma foto publicada no jornal The Guardian, com a imagem de uma jovem guia mostrando a vitrine do estabelecimento para turistas, sugere que a fachada do Cereal Killer Cafe tornou-se uma atração depois dos protestos. O lugar, assim, ficou mais interessante e atraente, pois foi o palco - e o motivo - para conflitos "autênticos". Ironicamente, o episódio deu ao café um toque de autenticidade e pertencimento a uma nova configuração do bairro. Embora a violência, o ruído e os protestos não sejam

3 Hipster é um termo em inglês, sem tradução para o português. Desde o início dos anos 2000, o termo tem sido usado no senso comum para designar pessoas jovens, principalmente homens brancos de classe média, que apresentam aparência (cortes de cabelo, barba, tatuagens, vestuário) e estilos de vida supostamente modernos, alternativos, boêmios, artísticos. O termo hipster costuma ser utilizado para descrever - em conversas informais, redes sociais, jornalismo, publicidade etc; ou em textos acadêmicos como a citação de Sharon Zukin (2010) neste artigo - algo ou alguém relacionado/a à moda, à tecnologia, à cultura não massiva. Entretanto, a cultura e a estética hipster não costumam escapar da lógica do consumo capitalista neoliberal, num ciclo contínuo de inovação e apropriação. 
características desejadas para um negócio, o evento parece ter adicionado mais camadas de valor à região comodificada. Meses depois, adesivos em forma de manchas de tinta podiam ser vistos nas janelas do café, anunciando seus produtos e instalações, mostrando que a estética do protesto foi apropriada pelos donos do estabelecimento.

\section{Os miseráveis de Knightsbridge}

A segunda intervenção que apresento foi realizada por um conhecido artista e ativista britânico. Na manhã de 24 de janeiro de 2016, uma obra de Banksy apareceu na rica área de Knightsbridge. Ele usou um tapume de construção localizado em frente à Embaixada da França para criticar o tratamento violento dado a refugiados. O trabalho faz referência à obra de Victor Hugo, Os Miseráveis, um dos romances históricos mais populares da França, que também pode ser lido como um manifesto humanitário. Nessa intervenção, Banksy reproduziu o famoso desenho da jovem personagem Cosette usado na divulgação do famoso musical Les Misérables.

A intervenção chama a atenção para o uso de gás lacrimogêneo pela polícia francesa contra refugiados do Jungle, um grande acampamento em Calais. A figura icônica no mural traz lágrimas nas faces e, como no cartaz do musical, uma bandeira francesa rasgada como pano de fundo. Embora a parte superior da obra de Banksy fosse semelhante à identidade visual do musical, sua parte inferior mostrava a imagem de uma nuvem de gás proveniente de uma lata com as iniciais CS, outro nome para gás lacrimogêneo. O mural retrata a frágil Cosette - representando os pobres, os fracos, os refugiados, os imigrantes - como vítima da violência perpetrada pelas forças policiais francesas.

Esta peça de arte de rua traz várias camadas de significado, pois consegue simultaneamente evocar um clássico da literatura francesa, um musical mundialmente famoso e uma prática de repressão. Como muitas outras intervenções urbanas feitas pelo artista sobre questões políticas controversas, o trabalho de Banksy é irônico e amargo. A justaposição dos elementos iconográficos contrastantes retrata a incoerência entre os ideais aclamados do humanismo e as práticas reais de tratamento desumano para com os excluídos.

A intervenção do artista faz sentido no lugar e na época em que foi feita; e pode ser considerada bastante ousada por ter sido realizada em espaço altamente monitorado de Londres, considerada a cidade mais vigiada por sistemas de câmera do mundo. Além disso, a ação não terminou no mural: no canto esquerdo da tela urbana, um código QR levava a um vídeo no YouTube com cenas do ataque policial com gás no acampamento de Calais. Assim, a imagem funciona como um apelo e um link para o vídeo. O trabalho ativista de Banksy é um exemplo da complexidade das interações urbanas e do fenômeno da convergência midiática (JENKINS, 2006). Nesta narrativa transmídia urbana, o artista usou recursos alternativos e complementares para comunicar, reforçar e comprovar o que tinha a dizer; utilizando ferramentas táticas ao interferir nos domínios do forte (CERTEAU, 1984). 
A obra de Banksy, embora coberta e removida no mesmo dia em que apareceu, foi, dentre as intervenções que observei na pesquisa, a obra mais fotografada, mais midiatizada e provavelmente a mais bem sucedida em seu objetivo político de chamar a atenção para o tratamento que as pessoas refugiadas em Calais recebiam. Essa intervenção também foi a mais «profissional»: feita por um artista anonimamente notório, foi reproduzida na mídia do Reino Unido e no exterior. Ao mesmo tempo, esta é também a intervenção mais comercializável porque, assim como outras obras do artista, o mural pintado certamente vale uma fortuna no mercado de arte.

\section{Considerações finais}

Intervenções contra as ações do mercado e dos governos não são um fenômeno novo. As estratégias retóricas, como a paródia e a crítica à publicidade, bem como a apropriação desses discursos contra-hegemônicos, são parte da lógica capitalista e do neoliberalismo. Há também uma relação especialmente ambivalente e imbricada entre cultura de rua transgressora e o fenômeno de comodificação da cidade, geralmente ligado ao turismo; e isso está ligado a questões de classe e de raça. Como observa Banet-Weiser (2012, p. 106. Tradução minha), "em cidades criativas que se desenvolvem junto a processos de gentrificação, a arte 'urbana' sinaliza uma presença racial desejável para investidores e turistas ricos em vez de corpos etnicamente diversos reais e indesejáveis". Ainda nesse sentido, Harvey (2012) observa que a singularidade e a transgressão são valorizadas à medida em que rompem a homogeneidade da produção de bens. A racionalidade neoliberal que sustenta o funcionamento do capitalismo na vida contemporânea precisa do dissenso, que tende a ser apropriado, transformado em consenso e vendido como marca de autenticidade e originalidade.

Minhas observações em Londres em 2015 e 2016, assim como o conjunto das imagens coletadas, revelaram questões controversas em evidência e disputa nas ruas: gentrificação, migração, Brexit, racismo, questões de gênero, uso de recursos públicos, preservação de culturas locais, vigilância etc. Considerando os casos analisados aqui, vejo o protesto contra o Killer Cereal Café em Brick Lane como cena de dissenso, precisamente porque um grupo subalterno forçou a mídia a lhes dar visibilidade por meio de táticas disruptivas. Suas reivindicações contra a gentrificação foram ouvidas, uma vez que a ação reforçou o problema como um objeto de debate público. No entanto, apesar da visibilidade, o resultado dessa ação direta é incerto e presumivelmente não muito bem sucedido: o processo de mercantilização da cidade conseguiu facilmente se apropriar, digerir e neutralizar os protestos.

Em Knightsbridge, o trabalho de Banksy é um exemplo da voz contra-hegemônica. O artista faz críticas ao consumismo, às guerras, à polícia, ao poder estabelecido, falando do ponto de vista de grupos excluídos. Entretanto, Banksy é também um artista renomado, 
um talentoso e competente empresário de si mesmo que sabe explorar o caráter "marginal" de sua atividade. Mesmo considerando que o trabalho de Banksy desafia as instituições hegemônicas, Banet-Weiser (2012, p. 94-95) vê o artista de rua como "uma marca em si mesmo" e um "empreendedor livre", no sentido neoliberal. Seu ato audacioso de fazer arte de protesto em uma área tão protegida agrega valor à sua intervenção, numa espécie de autenticidade que vem com a transgressão e a ilegalidade.

Neste artigo, escolhi analisar dois casos específicos de intervenções em Londres, em duas áreas diferentes, que chamaram a atenção da imprensa e do público para questões centrais nas discussões sobre o contexto urbano no Reino Unido e além, como a gentrificação e os conflitos relacionados às pessoas refugiadas. Ambos os temas refletem lutas sobre espaços e estão diretamente ligados a ideias de deslocamento. Esses dois processos têm pontos de crise na cidade global analisada, mas não são isolados nem inscritos apenas em um determinado tempo e espaço, pois fazem parte da história das cidades e das pessoas que nelas vivem.

Voltando à questão de pesquisa que propus, e buscando entender os impactos e os resultados das intervenções urbanas em um sentido maior e político, acredito que não há uma resposta definitiva ou «correta», pois o impacto concreto não é mensurável. Ao estudar estes e outros casos de inscrições urbanas, pude ver que as vozes dissidentes são, sem dúvida, fracas, não só pelas possibilidades limitadas de ação nos espaços urbanos, mas também pela dinâmica de apropriação e comodificação que constantemente tenta neutralizá-las. Ao olhar para Londres e outras cidades globais, podemos observar que, apesar das intervenções e protestos, a gentrificação segue como um fenômeno poderoso e em crescimento.

Os resultados mostram que quase nada escapa à lógica neoliberal, pois a apropriação diminui e assimila muitos tipos de protesto e crítica em intervenções urbanas. No entanto, não acredito que ela possa neutralizá-los completamente, pois essas intervenções nos lembram que a distribuição do sensível nunca é segura. Nesse sentido, ao causar pequenos distúrbios simbólicos, indivíduos e grupos ativistas fazem política. Há contradições em todos os casos analisados neste artigo, em diferentes níveis: os discursos e seus impactos são ambivalentes, mostrando crítica e apropriação. Ao assumir um conceito ampliado de dissenso, eu diria que a prática e a presença das intervenções podem configurar (em si) cenas de dissenso.

Concluo este artigo enfatizando a importância de abordar as intervenções urbanas como práticas de comunicação criativas que revelam as tensões, as relações de poder, o dissenso, bem como o consenso nas cidades globais. Eles interferem não apenas materialmente, mas na forma como entendemos e damos sentido ao mundo como um espaço de experiências vividas, interpretadas, mediadas e compartilhadas. As intervenções são importantes para a cidade enquanto espaço de mediação; podem mostrar consensos e também o dissenso, a falta e o excesso da vida contemporânea. Esses fenômenos 
são permeados pela lógica neoliberal e trazem consigo as contradições, a complexidade e as ambivalências presentes no cotidiano dos centros urbanos. Eles refletem e produzem o movimento, a instabilidade, a insegurança; já que as cidades e as sociedades não estão prontas nem perfeitas: estão sempre em processo de construção e também em processo de escrita.

Laura Guimarães Corrêa é professora adjunta no curso de Comunicação Social da Universidade Federal de Minas Gerais e docente permanente no PPGCOM-UFMG. Coordena o GrisPub (Grupo de pesquisa em publicidade, mídia e consumo). Tem mestrado e doutorado em Comunicação pela UFMG e é graduada em Publicidade e Propaganda pela mesma instituição. É diretora do Ciseco Centro Internacional de Semiótica e Comunicação.

guimaraes.laura@gmail.com>

\section{Referências}

ANTUNES, E.; VAZ, P. B. F. Mídia: um aro, um halo e um elo. In: GUIMARÃES, C.; FRANÇA, V. (Orgs.). Na mídia, na rua: narrativas do cotidiano. Belo Horizonte: Autêntica, 2006. p. 43-60.

BANET-WEISER, S. Authentic TM: the politics of ambivalence in a brand culture. Nova lorque: New York University Press, 2012.

BAUDELAIRE, C. Les Fleurs du Mal. Paris: Presse Pocket, 2007.

BENJAMIN, W. Magia e técnica, arte e política. São Paulo: Editora Brasiliense, 1994. (Obras escolhidas v. 1).

Rua de mão única. São Paulo: Editora Brasiliense, 1993. (Obras escolhidas v. 2).

CERTEAU, M. A invenção do cotidiano: artes de fazer. Petrópolis: Vozes, 2005.

DEBORD, G. Théorie de la dérive. Les Lèvres nues $n^{\circ}$ 9, 1956 e Internationale Situationniste $n^{\circ} 2$, 1958. Disponível em http://www.larevuedesressources.org/theorie-de-la-derive,038.html . Acesso em 10 fev 2018.

GEORGIOU, M. Media and the City: Cosmopolitanism and Difference. Oxford: Wiley, 2013.

Conviviality Is Not Enough: A Communication Perspective to the City of Difference. Communication, Culture \& Critique 10(2): 261-279, 2016.

JENKINS, H. Convergence Culture: Where Old and New Media Collide. New York, NY: New York University Press, 2006.

HARVEY, D. Rebel Cities: From the Right to the City to the Urban Revolution. London/New York, NY: Verso, 2012.

LEFEBVRE, H. O direito à cidade. São Paulo: Centauro, 2001.

LOPES, M. I. V. Mediação e recepção. Algumas conexões teóricas e metodológicas nos estudos latino-americanos de comunicação. Matrizes 8(1). São Paulo, ECA-USP, p. 1-18, 2014. 
MARQUES, Â. S. Sujeito. In: FRANÇA, V.; MARTINS, B. G. GRIS: trajetória, conceitos e pesquisa em comunicação. Belo Horizonte: Selo Ppgcom UFMG, 2014.

MARTíN-BARBERO, J. De los medios a las mediaciones. Barcelona: Gustavo Gili, 1987.

MASSEY, D. World City. Cambridge: Polity Press, 2015.

RANCIÈRE, J. O desentendimento: política e filosofia. London: Ed. 34, 1996.

A partilha do sensível: estética e política. São Paulo: EXO experimental org.; Ed. 34, 2009.

Dissensus: on politics and aesthetics. London: Bloomsbury Academic, 2015.

SILVERSTONE, R. Complicity and collusion in the mediation of everyday life. New Literary History 33(4): 761-80, 2002.

ZUKIN, S. Naked city: the death and life of authentic urban places. New York, NY: Oxford University Press, 2010

Artigo recebido em 15/02/2018

e aprovado em 03/10/2018. 